\title{
Tibia multiapikal deformiteleri ve tedavisi
}

\section{Tibia multi-apical deformities and their treatment}

\author{
Mustafa Çeliktaş ${ }^{1}$, Mahir Gülşen ${ }^{2}$ \\ ${ }^{1}$ İstinye Üniversitesi Tıp Fakültesi, Ortopedi ve Travmataoloji Anabilim Dalı, İstanbul \\ ${ }^{2}$ Adana Ortopedia Hastanesi, Adana
}

\begin{abstract}
Deformite ekstremitenin normal anatomiden sapması durumudur. Kısalık, rotasyon ve angulasyon hepsi ayrı birer deformitedir. Tibia kemiği özellikle travmaya daha fazla uğraması nedeni ile deformitelerin sık görüldüğü bir kemiktir. Sirküler eksternal fiksatörlerin en kolay uygulanabildiği kemik olmasından dolayı, açısal olarak büyük tibia deformiteleri sıklıkla eksternal fiksatörlerle başarı ile tedavi edilirler. Başarılı tedavi için deformitenin iyi değerlendirilmesi şarttır. Uniapikal deformitelerde proksimal ve distal eklem oryantasyon çizgilerinin kesişmesi ile oluşan CORA(Center Of Rotation Angle) görünen apeks seviyesindedir. Multiapikal deformitelerde ise oluşan CORA görünen deformite seviyesinde değildir ve bu CORA çözüm CORA'sı olarak adlandırılır. Doğru planlama yapmak için gerçek CORA'ları bulmak şarttır. Multiapikal deformitelerin tanınmaları bazı durumlarda zor olabilir. Özellikle ekleme yakın ek deformite varlığında kolaylıkla gözden kaçabilir. Multiapikal deformitenin uniapikal bir deformite gibi tedavi edilmesi durumunda ise eklem oryantasyonu bozulabilir veya kozmetik problemler ortaya çıkabilir.
\end{abstract}

Anahtar sözcükler: deformite; CORA; uniapikal; multiapikal
Deformity is a condition where the extremity deviates from normal anatomy. Shortness, angulation or rotations are different type of deformities. Tibia is a bone which deformities have seen frequently due to its close position to trauma. Large tibial deformities are often successfully treated with external fixators, since the bone is the easiest one to use circular external fixators. Accurate evaluation of deformity is essential for successful treatment. The CORA which is consisting of intersection between proximal and distal orientation lines is at the apparent level of deformity in uniapical deformities. The CORA is not at the level of apparent deformity in multi-apical deformities and this CORA called resolution CORA. It is essential to find the real CORAs for accurate planning. Recognition of multi-apical deformities can be difficult in some cases. It can easily be overlooked, especially in the presence of additional deformity close to the joint. If the multi-apical deformity is treated as a uni-apical deformity, joint orientation may be disrupted or cosmetic problems may occur.

Key words: deformity; CORA; uni-apical; multi-apical
B ir ekstremitenin deformitesi, normal anatomiden sapması demektir. Uzunluk farklılığı, rotasyon, angulasyon, translasyon hepsi ayrı birer deformitedir. Deformitenin tanımlanabilmesi için normal anatomiyi bilmek şarttır. Tedavide amaç normal anatomik durumu elde etmektir. Alt ekstremite deformite değerlendirilmesinde öncelikle dizilim (alignment) ve yönelim (orientation) kavramlarının anlaşılması gerekir. ${ }^{[1-4]}$

Dizilim (alignment): Kalça, diz ve ayak bileği ekleminin hizalanmasını belirtir.

Yönelim (orientation): Her ekstremite segmentinin ait olduğu eklem yüzeyi ile olan ilişkisini tarif eder (tibia ve femur).
Dizilim ve yönelimi iyi değerlendirebilmek için tüm alt ekstremitenin ayakta iken çekilen ön-arka radyografisine ihtiyaç vardır. Tüm planlamalar bu radyografiler üzerinde yapılacağından kurallara uygun olarak çekilmesi gerekmektedir. Rotasyon bozukluğu olmaması için patellanın tam önde, her iki femur kondillerinin ortasında görüldügü grafiler çekilmelidir. $\mathrm{Bu}$ radyografilerin çekilmesinde dikkat edilmesi gereken noktalar ve deformite dizilim yönelim bozukluğu analizi daha önceki bölümlerde anlatıldığından tekrar bahsedilmeyecektir.

Alt ekstremite deformitesine bağlı yakınmalar; yürüme bozukluğu, hareket kısıtlılığı, eklem çevresin-

- Illetişim adresi: Prof. Dr. Mustafa Çeliktaş, Maltepe, Çırpıcı Yolu B Çk. No.9, 34010 Zeytinburnu, İstanbul

Tel: 0532 - 7427255 e-posta: mstfceliktas@yahoo.com

- Geliștarihi: 28 Kasım 2019 Kabul tarihi: 20 Ocak 2020 


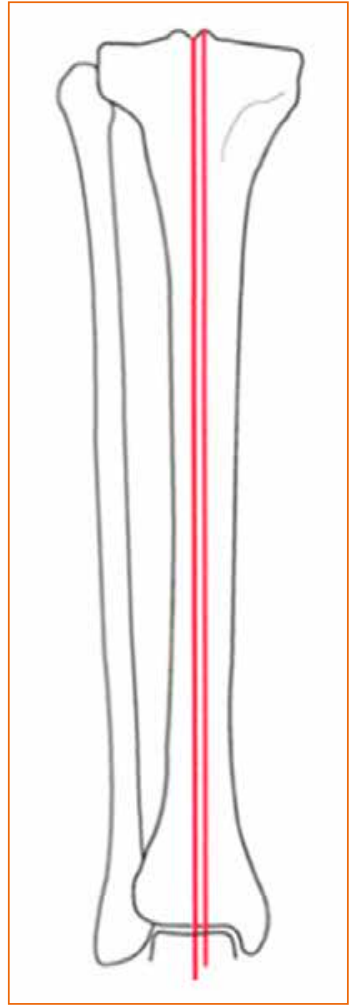

Şekil 1. Tibia mekanik ekseni anatomik eksenin birkaç milimetre lateralindedir. Pratikte aynı kabul edilir. de inflamasyon ve ağı olarak karşımıza çıkabilir. Hastaların aynı zamanda estetik, psikolojik yakınmaları da olabilir.

Deformite düzeltilmesinin amacı, varsa yakınmaları ortadan kaldırmak ve ilgili eklemlerde deformiteye ikincil gelişebilecek osteoartrozu önlemektir. Bunun için, sadece dizilimi düzeltmek değil, aynı zamanda her eklemin mekanik aksa (eksene) olan normal yönelimini sağlamak gerekir. Önemli olan, deformitenin tam olarak düzeltilmesi ve deformiteyi düzeltirken yeni bir deformite yaratılmamasıdır. Deformite düzeltilmesinin endikasyonları şunlardır ${ }^{[1,2]}$ :

1. Deformite hastada yürüyüş bozukluğu yaratıyorsa

2. Deformite hastada estetik ve psikososyal bozukluk yaratıyorsa

3. Deformite ağrı, topallama gibi klinik bulgular yaratiyorsa

4. Osteoartrit gelişmesine karşı önlem olarak

5. Proksimal tibial mekanik varus $5^{\circ}$ üzerinde ise

6. Mekanik aks (eksen) sapması (MAD) $15 \mathrm{~mm}$ üzerinde ise

7. Distal tibia prokurvatum deformitesi $15^{\circ}$ üzerinde ise

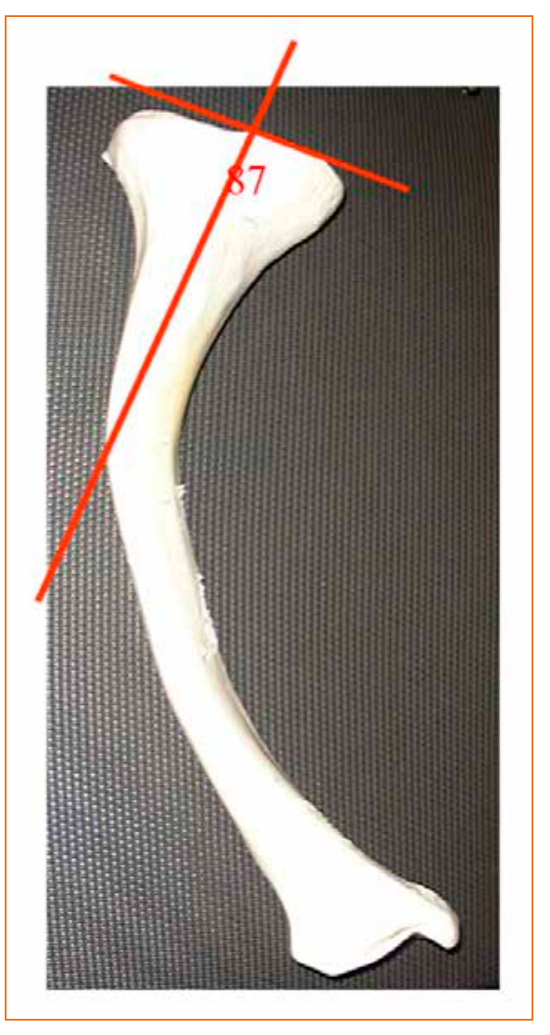

Şekil 2. Tibia proksimal mekanik ekseni çizilir. MPTA $87^{\circ}$ olarak alınır.
8. Distal tibia rekurvatum deformitesi $10^{\circ}$ üzerinde ise

9. Distal tibia frontal plan deformitesi $10^{\circ}$ üzerinde ise

Tibia aks sapmalarını hesaplamak femura göre daha kolaydır. Çünkü mekanik aks ve anatomik aks aynı kabul edilir. Aslında tibianın anatomik aksı mekanik aksının birkaç milimetre medialindedir, ancak iki eksen arasındaki açı $0^{\circ}$ olduğundan pratikte aynı kabul edilir (Şekil 1).

Alt ekstremitede deformiteden şüpheniliyorsa öncelikle alt ekstremite dizilim bozukluğu testi yapmamız gerekir. Öncelikle alt ekstremite mekanik aksı (ekseni) çizilir. Alt ekstremitenin mekanik ekseni, diz merkezinin ortalama $8 \pm 7 \mathrm{~mm}$ medialinden geçer. Eğer aksta bozukluk varsa malaligment (dizilim bozukluğu) var denir ve deformitenin nereden veya nerelerden kaynaklandığı bulunmaya çalışılır. Sırasıyla femur, tibia, diz eklemi çizgileri, diz eklemi subluksasyonları, ve femur kondili tibia platosu değerlendirilir. ${ }^{[4]}$

Bu bölümde konumuz tibia deformiteleri olduğundan diğer ölçümlerin normal, tibiada ise MPTA'nın (medial proksimal tibial açı) anormal olduğu durumdan bahsedilecektir. 


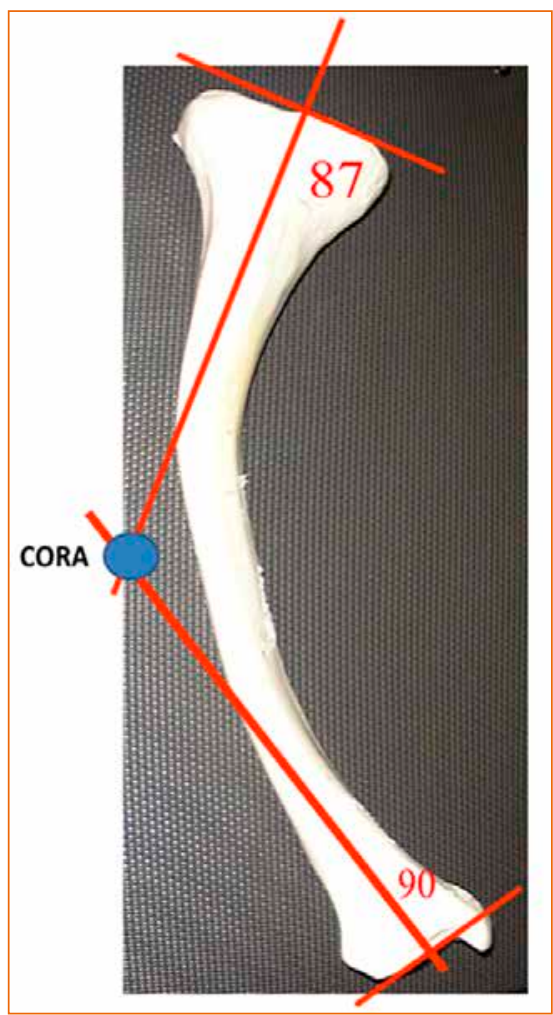

Şekil 3. Tibia distal mekanik ekseni çizilir. LDTA (lateral distal tibial açı) $90^{\circ}$ olarak alınır. iki eksenin kesiştiği yer CORA'dır.

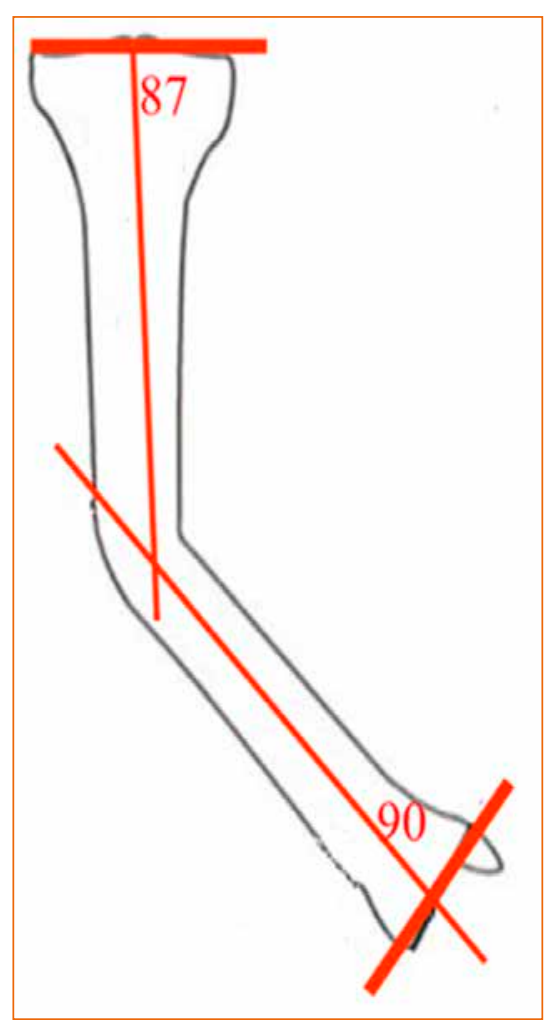

Şekil 4. Uniapikal deformitelerde CORA görünen apeks seviyesindedir.
Tibiada deformite olduğu tespit edildikten sonra ayrıntılı olarak maloryantasyon değerlendirmesi yapmak gerekir. Bu amaçla tibiada anatomik veya mekanik eksen kullanılabilir.

1. Tibia proksimal mekanik ekseni çizilir (Şekil 2).

2. Tibia distal mekanik ekseni çizilir (Şekil 3).

Proksimalden gelen ve distalden gelen eksen çizgileri kesiştirilerek CORA bulunur. CORA, Center of Rotation Angle kelimelerinin baş harflerinden oluşur. Deformitenin merkezi olan yerdir (Şekil 3). Birçok deformitede CORA bölgesinde deformitenin apeksi bulunur. Apeks deformitenin görünen tepe noktası olarak adlandırılabilir.

Proksimal ve distal eksenler görünen deformite apeksinde kesişiyorsa, bu deformite uniapikaldir (Şekil 4). ${ }^{[4]}$

Proksimal ve distal eksenler görünen deformite apeksinde kesişmiyorsa, bu deformite multiapikaldir. ${ }^{[4]}$ Multiapikal diyafizer deformitelerde bunu anlamak oldukça kolaydır: CORA kemik üzerinde değil kemik dışında oluşur (Şekil 3). Ama bu kural her zaman geçerli değildir. Eğer ekleme yakın bölgelerde ikinci bir deformite varsa ve anatomik akslar üzerinden çalışılıyorsa, multiapikal deformite kolayca uniapikal deformite gibi algılanabilir. Bu nedenle eklem oryantasyon çizgileri proksimal ve distalde çizilerek değerlendirme yapmak daha uygundur. Şekil 5 ve 6'da bu durum bir örnek ile anlatılmaya çalışılmıştır.

Deformitenin uniapikal mi, yoksa multi apikal mi olduğunu anlamak önemlidir. Deformite düzeltilmesindeki amaç sadece dizilimi normal hale getirmek değil, aynı zamanda her eklemin mekanik aksa olan normal yönelimini yerine getirmektir. ${ }^{[3]}$ Multiapikal deformiteyi uniapikal deformite gibi düşünüp CORA noktasından osteotomi yapılırsa yönelim (orientation) düzelir. Ama kemiğin anatomik aksı zikzak çizer. Femur gibi çevre yumuşak dokuların fazla olduğu bölgelerde bu kusur kısmen gizlense de özellikle tibia gibi cilt altı yerleşimli kemiklerde kozmetik bir problem ortaya çıkar (Şekil 7). Eğer deformite ekleme yakın bir deformiteyse anatomik aks düzelmesine rağmen mekanik aksın ve eklem oryantasyonunun bozulduğu görülür.

Tüm bu problemlerin önüne geçmek için ölçümleri oldukça dikkatli yapmak gerekir. Multiapikal deformitelerde yani aks çizgilerinin kemik dışında kesiştiği deformitelerde bulunan CORA "çözüm CORA" sı olarak 


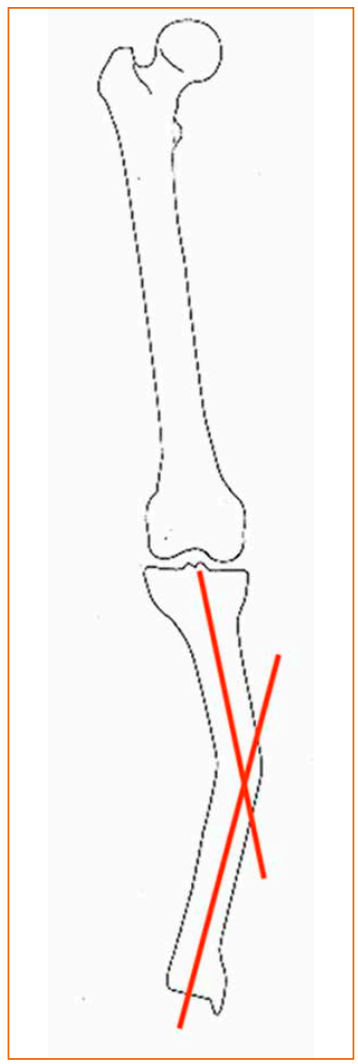

Resim 5. Ekleme yakın deformite varlığında ve anatomik akslar kullanılarak deformite değerlendirildiğinde multiapikal deformiteler yanlış olarak uniapikal gibi algılanabilir. Çünkü şekilde olduğu gibi aşikâr olan diyafizer deformitenin CORA'sı görünen apekste ve kemik üzerinde çıkmıştır. Eklem oryantasyonları çizilerek ikinci bir deformitenin varlığı araştırılmazsa hatalı planlama yapılabilir.

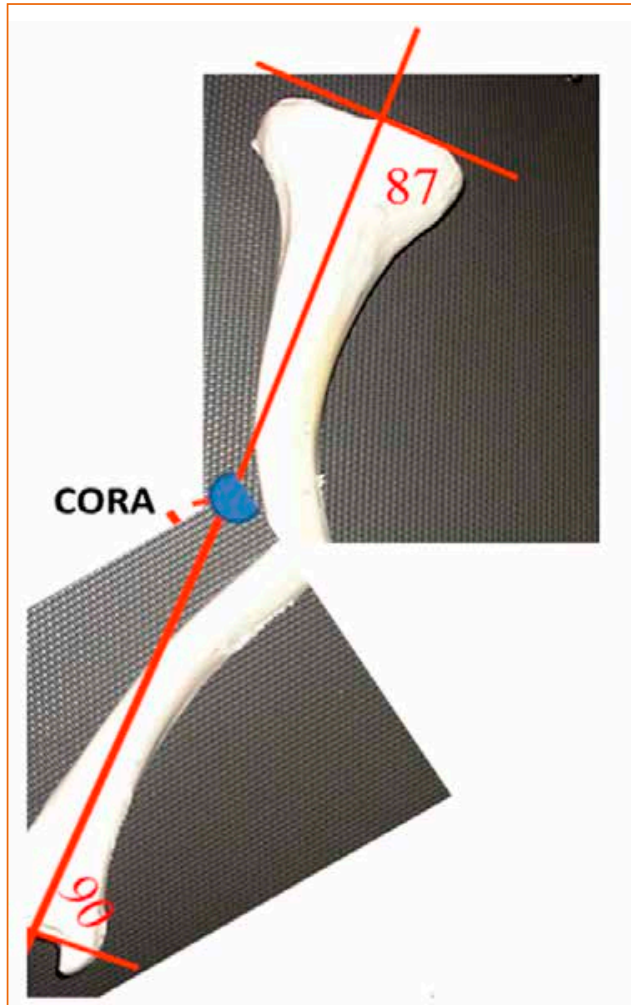

Şekil 7. Multiapikal deformite uniapikal gibi tek CORA üzerinden düzeltilirse her ne kadar oryantasyon düzeltilse de kemiğin anatomik aksı zigzag çizer.

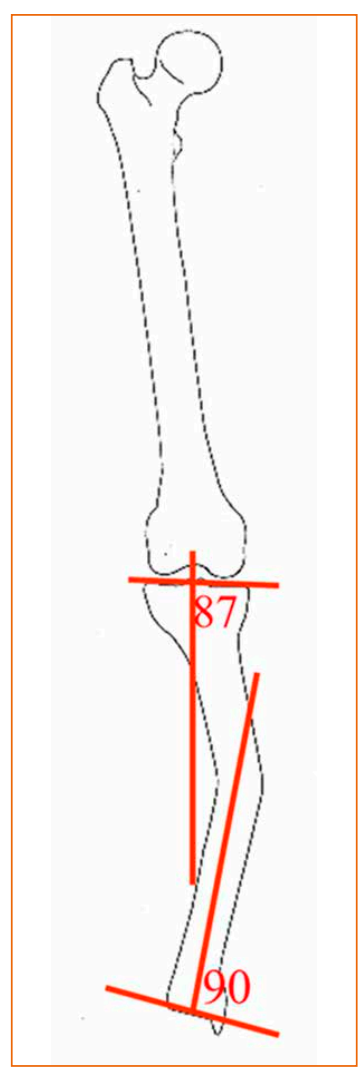

Şekil 6. Aynı deformiteyi eklem oryantasyon çizgilerine uygun olarak mekanik akslar üzerinden değerlendirdiğimizde, aks çizgilerinin görünür deformite üzerinde kesişmediğini; yani aslında deformitenin multiapikal olduğunu görebiliriz. adlandırılır. Deformiteyi mekanik, anatomik ve kozmetik olarak tedavi etmek için "gerçek CORA" ların bulunması gerekir. Bu amaçla ara kemik segmentinin anatomik aksı çizilir. Bu aksın proksimal segmentin mekanik ekseniyle kesiştiği nokta CORA 1; distal segmentin mekanik ekseniyle kesiştiği nokta CORA 2 olarak adlandırılır (Şekil 8). CORA 1 ve 2 gerçek CORA'lardır. Gerçek CORA'larda çözüm CORA'sından farklı olarak apeks bulunur. Yani CORA 1'de ve CORA 2'de birer apeks vardır.

CORA 1 ve 2'deki deformitenin açısal değeri ayrı ayrı hesaplanır. ílizarov prensiplerine bağlı kalınarak frame(çerçeve) kurulur. Kirshner tellerini geçerken her bir deformitenin düzeltilmesi için gereken kuvvet vektörü yönleri, başparmak kuralına göre ayrı ayrı değerlendirilip telleri o yönlere göre geçmek gerekir. Sistem kurulduktan sonra CORA 1 ve 2'den osteotomi yapılır ve deformite düzeltilir (Şekil 9). Böylece hem anatomik, hem mekanik aks düzeltilmiş ayrıca kozmetik problemi olmayan ekstremite elde edilmiş olur.

Şekil 10'da multiapikal deformitesi olan bir hastanın tedavi aşamaları gösterilmiştir. 


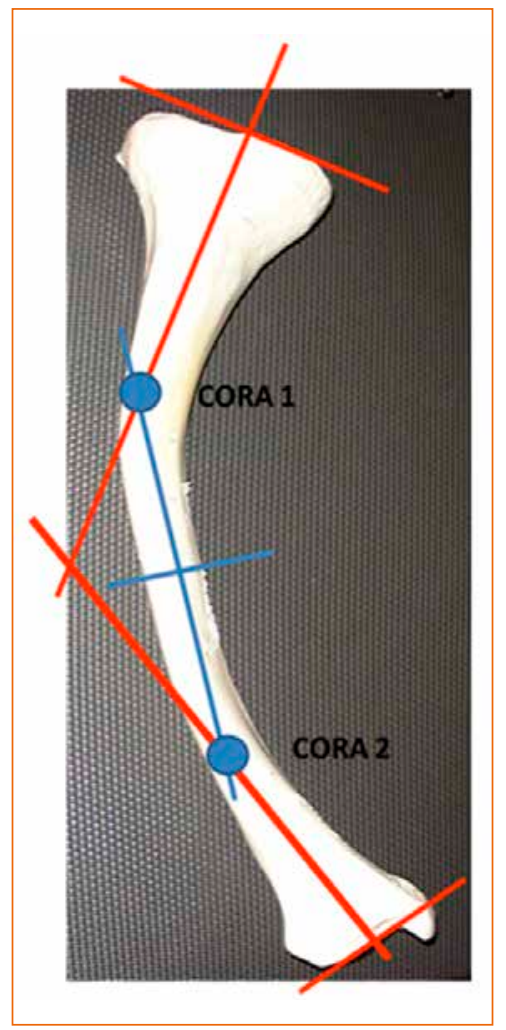

Şekil 8. Gerçek CORA'ları bulmak için ara segmentin anatomik aksı çizilir. Bu aksın proksimal segmentin mekanik ekseniyle kesiştiği nokta CORA 1, distal segmentin mekanik ekseniyle kesiştiği nokta CORA 2 olarak adlandırılır.

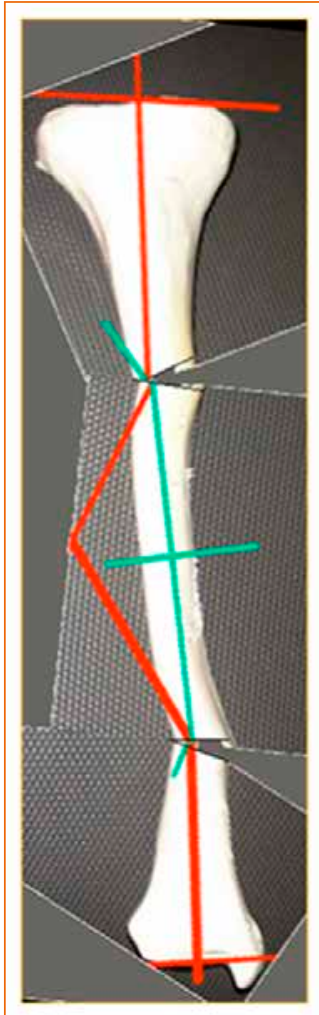

Şekil 9. Gerçek CORA'ların her ikisinden de osteotomi yapılıp hesaplanan değerlere göre açısal düzeltme yapılır. Sonuçta anatomik mekanik ve kozmetik açıdan düzgün ekstremite elde edilir.
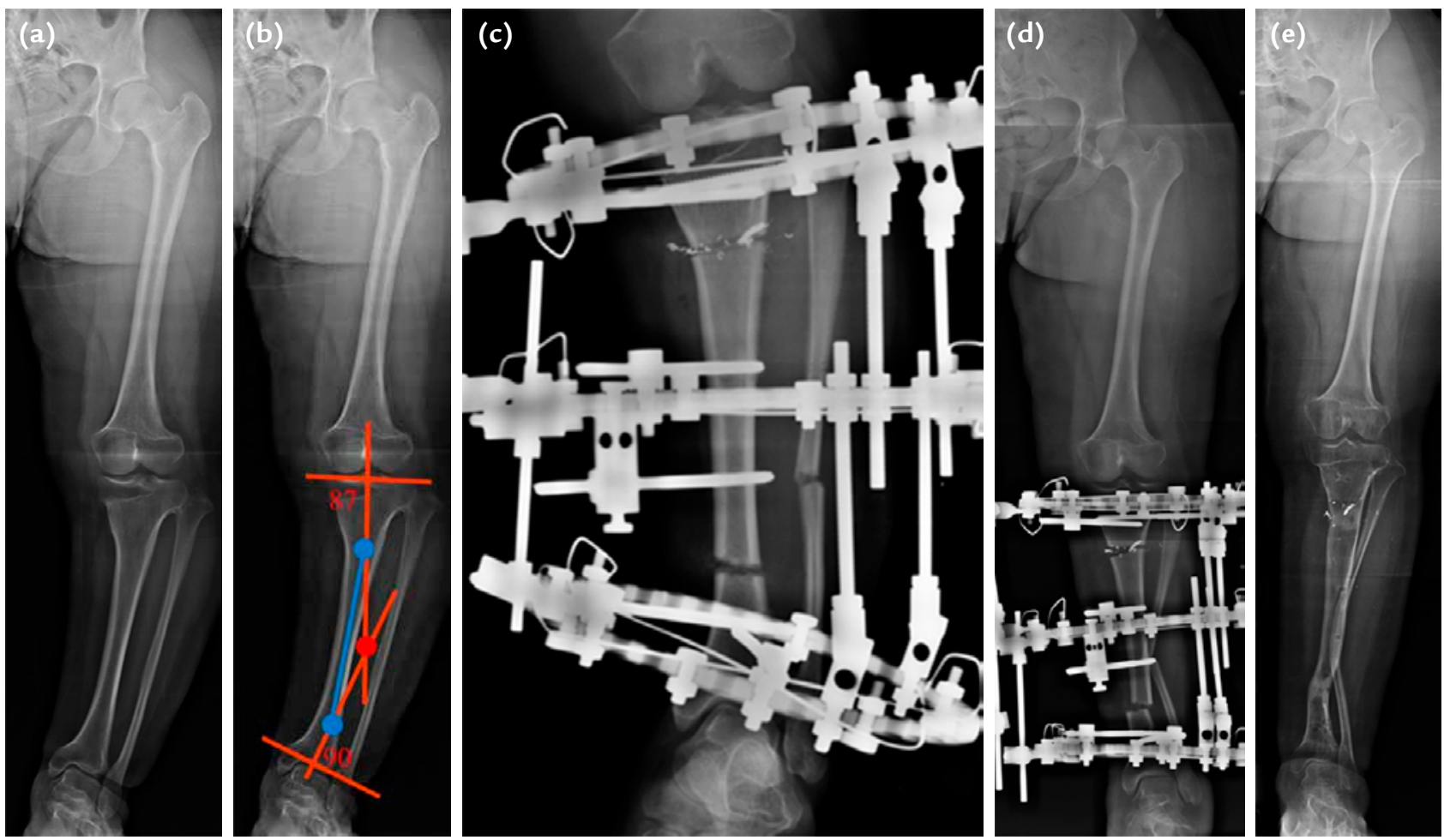

Şekil 10. a-e. Yirmi yaşında tibia varus deformitesi olan hasta (a).Yirmi yaşında tibia varus deformitesi olan hasta. Yapılan ölçümlerde tibiada multiapikal deformitesi olduğu görülüyor (b). Yirmi yaşında tibia varus deformitesi olan hasta. Ölçümlere sadık kalınarak Ilizarov EF sistemi kurulup tibia proksimal ve distalden osteotomiler yapılıyor. Her bir deformite için ayrı menteşe yerleştirildiğine dikkat ediniz (c). Deformiteler düzelmiş; konsolidasyon bekleniyor (d). Hastanın ilizarov eksternal fiksatörü çıkarıldıktan sonraki takip grafisi. Dizilim ve yönelim düzelmiş durumda (e). 


\section{KAYNAKLAR}

1. Çakmak M, Civan M. Multiapikal deformiteler. İçinde: Çakmak M, Şen C, editörler. Deformite Cerrahisinde Ilizarov Uyygulamaları. İstanbul: Nobel Tıp Kitabevleri; 2014. ss.52-9.

2. Gülşen M. Deformite Düzeltilmesi Prensipleri. İçinde: Çakmak M, Şen C, editörler. Deformite Cerrahisinde ilizarov Uygulamaları. İstanbul: Nobel Tıp Kitabevleri; 2014. ss.145-66.
3. Gülşen M, Onac E. 1. İleri İlizarov Kursu Ders Notları. Çukurova Üniversitesi Tıp Fakültesi, Ortopedi ve Travmatoloji Anabilim Dalı, Adana, 1997.

4. Paley D. Frontal plane mechanical and anatomic axis planning. In: Paley D. Principles of Deformity Correction. Berlin: Spinger Verlag; 2002. pp.61-97. 